\title{
Laboratory Tests of Window-Wall Interface Details to Evaluate the Risk of Condensation on Windows
}

Wahid Maref ${ }^{1}$, Nathan Van De Bossche ${ }^{2}$, Marianne Armstrong ${ }^{1}$, Michael A. Lacasse ${ }^{1}$, Hakim Elmahdy ${ }^{1}$ and Rock Glazer ${ }^{1}$

1-National Research Council Canada, Institute for Research in Construction, Ottawa, ON, Canada

2-Ghent University, Department of Architecture and Urban Planning, Ghent, Belgium

\begin{abstract}
The development of alternative details to manage water intrusion at the window-wall interface has produced a number of novel approaches to detailing the interface between the window and adjacent wall assembly. Many of these approaches advocate the need to provide drainage at the rough opening of the window subsill given that the window components themselves are susceptible to water entry over their expected life. Depending on the types of windows used and the cladding into which the windows are installed, there arise different methods to provide drainage that may also affect air leakage through the assembly. This in turn may give rise to the formation of condensation along the window at the sill or along the window sash and glazing panels. Hence there is a need to determine if, under cold weather conditions, specific interface details that incorporate sill pans provide potential for condensation on the window components in which air leakage paths may be prominent at the sill or elsewhere on the window
\end{abstract}


assembly. The paper reports on a laboratory evaluation of conditions suitable for the formation of condensation at the window frame perimeter of the interface assembly as a function of both temperature deferential and air leakage rate across the test assembly. A summary of the laboratory test protocol is provided that includes a description of the test set-up and apparatus, fabrication details of the specimen and information on instrumentation and calibration and experimental results for one type of window (flange window). In parallel, preliminary simulation results were presented and compared to those obtained from experiment using the commercially available thermal software BISCO.

Keywords: air leakage, laboratory testing, window installation, wall-window interface, window condensation, 


\section{Introduction}

There exist several standard methods for determining the potential for the formation of condensation on windows, as provided in Table 1, however the essential aspects of the method were first proposed by Sasaki [1] and the standardisation work carried out in AAMA [2,3], ASTM [4] and CSA [5] follows on these initial efforts. These standards prescribe the overall test protocol, temperatures of the room side and cold side, and maximum relative humidity under test conditions. A useful overview of these methods is given by Elmahdy [6].

Table 1 - List of standards for determining condensation potential of windows

\begin{tabular}{|l|l|l|l|l|l|}
\hline \multicolumn{1}{|c|}{ Org. } & \multicolumn{1}{|c|}{$\begin{array}{c}\text { Standard } \\
\text { designation }\end{array}$} & $\begin{array}{c}\text { Room side } \\
\text { Temp. } \\
\left({ }^{\circ} \mathrm{C}\right)\end{array}$ & $\begin{array}{c}\text { Cold side } \\
\text { Temp. } \\
\left({ }^{\circ} \mathrm{C}\right) \_\end{array}$ & $\begin{array}{c}\text { TEST } \\
\text { PERIOD }\end{array}$ & $\begin{array}{c}\text { Pressure / } \\
\text { \%RH }\end{array}$ \\
\hline AAMA & $\begin{array}{l}\text { AAMA 1502.3/ } \\
\text { AAMA 1503-98 }\end{array}$ & $21.1\left(70^{\circ} \mathrm{F}\right)$ & $-17.8\left(0^{\circ} \mathrm{F}\right)$ & & $\mathrm{Nil} /<15 \%$ \\
\hline ASTM & ASTM C1199-00 & $21.1\left(70^{\circ} \mathrm{F}\right)$ & $-17.8\left(0^{\circ} \mathrm{F}\right)$ & & $\mathrm{Nil} /<15 \%$ \\
\hline CSA & CSA A 440.2-04 & $20 \pm 1$ & $-30 \pm 1$ & $5 \mathrm{~h}\left(<1{ }^{\circ} \mathrm{C}\right)$ & $0 \pm 5 \mathrm{~Pa} /<15 \%$ \\
\hline
\end{tabular}

There also exist simulation tools that could be used to assess the potential for window condensation such as, for example, FRAME4.0 [7], VISION 4.0 [8] and BISCO 10.0 [9].

Provided details of the window profile are available in the format accessible by the simulation software, such tools permit standard window types to be readily assessed from known boundary conditions and rapid evaluations on the energy efficiency as well as condensation potential are possible. However, such software is not typically adaptable to measuring the performance of window installation in which nonstandard conditions and different approaches might be of interest as, for example, where air leakage is considered a testing and evaluation parameter [10]. 


\section{Method for Determining Condensation Potential}

The essential elements of the method, briefly described, consist of testing a window in a hotbox chamber, measuring the window and frame surface temperatures at specified locations on the window, and calculating a weighted average of the interior surface temperature. The "Temperature index" $(I)$ is then determined based on the following relationship and on CSA Standard:

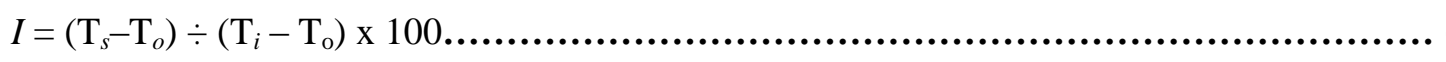

where $\mathrm{T}_{i}$ and $\mathrm{T}_{o}$ are the indoor and outdoor air temperatures in ${ }^{\circ} \mathrm{C}$, and $\mathrm{T}_{s}$ is the average room-side surface temperature measured in the test.

For the equation (1) to be used internationally we used different definition of the temperature index according to EN ISO 10211:2007 [11]:

$$
I=\left(\mathrm{T}_{s}-\mathrm{T}_{o}\right) \div\left(\mathrm{T}_{i}-\mathrm{T}_{\mathrm{o}}\right)
$$

The Temperature Index is non-dimensional, and represents the interior surface temperature relative to the interior and exterior air temperatures. $I=0$ implies $\mathrm{T}_{s}=\mathrm{T}_{o}$, which is the same as having no window at all (because the interior surface temperature is the same as the outdoor temperature. When the temperature Index, $I=1$, this indicates that $\mathrm{T}_{s}=\mathrm{T}_{i}$, the same as the room-side air temperature thus providing the best possible rating. Based on equation (2), I may range between 0 and 1, with a typical value for a clear double-glazed window having a metal frame being ca. $I=0.4$. Thus using Equation (2) to predict condensation potential of a given window in a room, the following information is required:

- $\quad$ The $I$ (temperature index) value for the window;

- The indoor room air temperature $\left(\mathrm{T}_{i}\right)$ and outdoor temperature $\left(\mathrm{T}_{o}\right)$ at the location of interest

- The relative humidity or dew point temperature of the room air. 
Based on this information, the estimated room-side surface temperature $\left(\mathrm{T}_{s}\right)$ can be determined and thereafter compared to the dew point temperature. The dew point temperature of the indoor air can be calculated according to equations 3 and 4 (EN ISO 13788:2001 [12]):

$\theta=\frac{237.3 * \log _{e}\left[\frac{P_{\text {sat }}}{610.5}\right]}{17.269-\log _{e}\left[\frac{p_{s a t}}{610.5}\right]}$ for $\mathrm{p}_{\mathrm{sat}} \geq 610.5 \mathrm{~Pa}$

$\theta=\frac{265.5 * \log _{\varepsilon}\left[\frac{P_{\text {gat }}}{6110.5}\right]}{21.875-\log _{\varepsilon}\left[\frac{P_{\text {gat }}}{610.5}\right]}$ for $\mathrm{p}_{\text {sat }}<610.5 \mathrm{~Pa}$

If the value of $\mathrm{T}_{s}$ is less than that of the dew point temperature inside the room then condensation on the window is expected. An overall condensation risk assessment methodology is presented in EN ISO 13788:2001 [12].

\section{Overview of Approach}

The development of alternative details to manage water intrusion at the window-wall interface has produced a number of new approaches to detailing the interface between the window and adjacent wall assembly. Many of these approaches advocate the need to provide drainage at the rough opening of the window sill given that the window components are susceptible to water entry over their expected life. Depending on the types of windows used and the cladding into which the windows are installed, there arise different methods to provide drainage that may also affect air leakage through the assembly. This in turn may give rise to the formation of condensation along the window at the sill or along the window sash and glazing panels. Hence there is a need to determine if, under cold weather conditions, specific interface details that incorporate sill pans provide potential for condensation on the window components in which air leakage paths may be prominent at the sill or elsewhere on the window assembly.

As has been shown, several methods have been devised to evaluate the potential for condensation at the window proper; however, there have not yet been any methods specially derived for evaluating the formation of condensation at windows given different window installation details. Such a method would 
permit determining if a window installation provides adequate thermal resistance and reduced risk to the formation of condensation. It would also permit comparative evaluations amongst different installation methods using the same window and cladding types in a given wall assembly. It may also offer a means to benchmark the results of a field-testing method, should one be developed in the future.

This paper reports on a laboratory evaluation of conditions suitable for the formation of condensation at the window frame perimeter of the interface assembly as a function of both temperature deferential and air leakage rate across the test assembly. A summary of the laboratory test protocol is provided that includes a description of the test set-up and apparatus, fabrication details of the specimen and information on instrumentation, calibration and experimental results for one type of window (flange window). In parallel, preliminary simulation results were presented and compared to those obtained from experiment using the thermal software BISCO version 10.0 [9].

\section{Outline of Evaluation Program}

Testing was conducted in a hotbox test facility [13] and the CSA A440.2 test method for determining window condensation [5] was adapted to subject specimens to specified temperature differences. A suitable specimen, incorporating a window and related interface details, was subjected to temperature differentials from which surface temperature measurements on specific components of the window were determined. This information permitted establishing whether there existed conditions suitable for the formation of condensation given specified interior and exterior conditions. A description of the hotbox is provided by Brown [14] and details on the experimental procedure, the calibration of the hotbox, specimen instrumentation and data acquisition are provided in subsequent sections.

Given that the primary interest was to determine whether different window installation details affect the potential risk to the formation of condensation on a window, the different issues arising from this relate to the following: 
- Selection of type of wood frame assembly and assembly components including size of frame, sheathing board, insulation and window types,

- Location of window in window opening

- Choice of installation details, including, sill pan flashing, other flashing

- Incorporation of "deficiencies" in the specimen

One might consider that in North America a typical wood frame assembly for cold climates would consist of a 6-in wood stud wall, sheathed with an OSB panel and incorporating a polyolefin sheathing membrane, fiberglass insulation, polyethylene vapour barrier, and interior gypsum board finish. This was assumed to be a representative assembly in which non-operable PVC windows of two different types were installed: windows incorporating a fixing (installation) flange (i.e. flanged window), and those not having a flange (i.e. box window). PVC windows were selected as these were considered to be the most commonly specified in large commercial housing projects.

This paper reports on results derived from testing flanged windows. For flanged windows, the location of the window is fixed in relation to the plane of thermal resistance of the wall (Figure 1); this necessarily affects the overall thermal insulation (RSI-value; i.e. R-value in SI units) at the opening. When a window incorporating a fixed flange is installed, as shown in Figure 1, the location of the plane of thermal resistance is predetermined, based on the location of the flange in relation to the windowpane and window frame. In this instance, the plane of thermal resistance of this window may very well be forward of that of the nominal plane of thermal resistance of the wall.

\section{Figure 1 - Schematic of flanged window installation in window opening showing the planes of thermal resistance of window in relation to that of nominal wall assembly}

As the difference between the locations of these two planes increases, so too does the likelihood for the formation of condensation on the window or frame, for windows installed in cold climates. This is due to 
the fact that there is less thermal insulation in the cavity between the window and the window opening as compared to the wall proper thus giving rise to decreases in surface temperature of the window or window frame on the interior in relation to the interior room temperature. The continuity of the thermal plane at the window interface with the wall must, in principle, be reconciled; nonetheless, this is limited by the amount of space in which insulation can be applied even though the products typically used have themselves high thermal resistance.

In respect to the choice of installation details, consideration was only given to those details that had in a previous study $[15,16]$ demonstrated an ability to adequately manage rainwater entry. Such installation details typically include a sloped sill with sill pan flashing incorporating a back dam.

Finally, given the interest in using installation details that include a sill pan, thought was given to possible paths of air leakage through the assembly at the sill and the type of deficiencies that might arise at these locations due to improper installation of components or premature failure of seal components. Two possible paths were considered: a short path at the sill and another longer path along the interior jamb that enters the room side at the window head.

Detailed information is provided in the subsequent section on the configuration of the test specimens, the window installation and location of the window in the specimen, and the incorporation of deficiencies in the specimens to simulate air leakage problems.

\section{Experimental Set-Up and Procedures}

\section{Configuration of Test Specimen and Mounting Specimen in Test Assembly}

Figure 2 provides the nominal test specimen set-up showing the wood frame assembly and the size of opening for and its location within the assembly of a non-operable PVC window. The nominal size of the 
test frame incorporating the window-wall interface was $1.22-\mathrm{m}(4-\mathrm{ft}$.$) wide by 2.44-\mathrm{m}(8-\mathrm{ft}$.$) high. The$ test assembly was intended to be representative of typical North American wood frame construction practice. The wall assembly was framed with 51 by $152-\mathrm{mm}$ (2 by 6-in.) SPF lumber in the configuration shown in

Figure 2. The exterior cladding of the assembly was hardboard wood composite siding, installed in accordance with current building practice, and directly to the sheathing membrane (spun bonded polyolefin). The membrane overlays an oriented strand board (OSB; 11-mm) sheathing panel affixed over the wood frame. Fiberglass batt type insulation was placed in the stud cavities adjacent to the window opening and the interior finish was gypsum board (12.7-mm).

A non-operable PVC window (610-mm by $1220-\mathrm{mm})$ incorporating a fixing (installation) flange (i.e. flanged window) was installed in the specimen. These were the same type of window as was used in a previous study to evaluated the watertightness of different window installation details $[15,16]$, and are typical of those specified for North-American construction practice. The location of a flanged window in the window opening, as was previously discussed, is necessarily predetermined by the configuration of the flange in the window frame. Table 2 provides information on the respective values of RSI for each of the relevant wall components from which the location of the plane of thermal resistance was determined; the line in the table that separates the two values of fibreglass batt indicates the plane of thermal resistance, i.e. the location within the wall assembly on either side of which the cumulative values for RSI are equal (i.e. 2.7-in.). Figure 3 provides the installation details of a flanged window incorporating the self-adhering flexible pan flashing membrane, sloped sill, up-stand or related component details that help promote drainage of water from the windowsill if subjected to inadvertent water entry. Figure 3 also shows that the location of the insulated glass unit, assumed to be the plane of thermal resistance of the window, differs from that of the wall and indeed is located closer to the exterior of the wall.

Table 2 - RSI value of wall components and calculation location of plane of thermal insulance of wall 


\begin{tabular}{|l|c|c|c|c|}
\hline \multicolumn{1}{|c|}{ Component } & $\begin{array}{c}\text { Thickness } \\
{[\mathrm{m}(\mathrm{in} .)]}\end{array}$ & $\begin{array}{c}\text { Thermal } \\
\text { resistivity } \\
{[\mathrm{m} \mathrm{K} / \mathrm{W}]}\end{array}$ & $\begin{array}{c}\text { Thermal } \\
\text { resistance } \\
\left.\text { RSI [m }{ }^{2} \mathrm{~K} / \mathrm{W}\right]\end{array}$ & $\begin{array}{c}\text { Cumulative } \\
\text { RSI }\end{array}$ \\
\hline Wall-outside air film, 24 km/h & --- & 0.03 & 0.030 & 0.030 \\
\hline Siding - hardboard & $0.0111(7 / 16)$ & 10.75 & 0.120 & 0.150 \\
\hline Sheathing - OSB & $0.0111(7 / 16)$ & 11 & 0.122 & 0.272 \\
\hline Fiberglass Batt & $0.0685(2.7)$ & 26 & 1.798 & 2.070 \\
\hline Fiberglass Batt & $0.0712(2.8)$ & 26 & 1.872 & 3.942 \\
\hline Drywall & $0.0127(0.5)$ & 6.2 & 0.079 & 4.021 \\
\hline Inside Air Film (non reflective, vertical) & --- & 0.120 & 0.120 & 4.141 \\
\hline Total & $0.175(6.9)$ & & $\mathbf{4 . 1 4 1}$ & \\
\hline
\end{tabular}

Figure 2 - Nominal test specimen set-up showing wood frame assembly of the test specimen and size and location within assembly of non-operable vinyl window

Figure 3 - Vertical Section of specimen showing installation details for non-operable - flanged window- shows plane of thermal resistance of window unit as compared to wall

Figure 4 - Isometric view of specimen; shows location of deficiency at lower corner of window and alternate leakage path at top of window

A summary of the different interface details for flanged windows are given in Table 3, in which information is provided on the:

- Type of window (flanged) and the position of the window in the rough opening; In Table 3, "Position" refers to the position of the window in the rough opening; flange implies that the plane is determined on the basis of where the flange of the window is located in relation to the respective planes of thermal resistance;

- Use, or not, of insulation and the type of insulation used when specified; "Batt" refers to fiberglass batt insulation, whereas the SPF designation indicates that polyurethane spray-in-placefoam was used in the same cavities located between the window opening and window frame.

- Incorporation, or not, of deficiencies in the assembly; D1 in Table 3 was located at the exterior of the wall-window interface and at the juncture of the cladding and window frame at the lower extreme comer of the window (Figure 4); D3 in Table 3 was located at the interior of the 
assembly and at the interface between the window frame and the interior finish but located at the upper most corner of the window assembly.

The introduction of deficiencies at the wall-window interface provided a means to evaluate whether air leakage across different components of the window assembly could cause condensation to form on the warm side of the wall assembly when leakage was induced in the test assembly. The intent was to demonstrate the vulnerability of the assembly to the formation of condensation on the interior in instances where, for example, a deficiency was located as shown in Figure 4 as D1 on the exterior and D3 on the interior.

Table 3 - Test series for flanged window configuration

\begin{tabular}{|c|c|c|c|c|c|c|}
\hline \multirow{2}{*}{ Flanged installation } & \multicolumn{2}{|c|}{ Test Set 4 } & \multicolumn{2}{c|}{ Test Set 5 } & \multicolumn{2}{c|}{ Test Set 6 } \\
\hline Position & Flange & Flange & Flange & Flange & Flange & Flange \\
\hline Insulation type & NONE & NONE & Batt & Batt & SPF & SPF \\
\hline Deficiency type / location & NO & YES & NO & YES & NO & YES \\
\hline & & D1+D3 & & D1+D3 & & D1+D3 \\
\hline & & & & & & \\
\hline
\end{tabular}




\section{Instrumentation and Data Acquisition}

Measurement of temperatures and relative humidity - The chamber environmental conditions were monitored continuously over the course of a test sequence; likewise surface temperatures on the interior and exterior surface of the window and window frame were measured; the following provides information on accuracy of measurements and the means of capturing data.

Monitoring chamber conditions - Both the temperature and relative humidity $(\mathrm{RH})$ was continuously monitored over the course of a test sequence in the warm side chamber and only temperature in the cold side chamber. Measurements of temperature was made to an accuracy of $\pm 1.5^{\circ} \mathrm{C}$ and that of relative humidity to $\pm 1 \% \mathrm{RH}$. The data was recorded on the data acquisition system then subsequently used to ensure that steady state conditions have been maintained over the course of a test sequence.

Monitoring and recording surface temperature condition - Surface temperature conditions on either side of the window (i.e. exterior and interior) and on specified window components (e.g. window lite; window frame at sill, frame at jambs, etc.) was continuously monitored with the use of a set of forty 40 thermocouples, 20 were used on the exterior, and 20 on the interior of the specimen. Measurements of temperature were made to an accuracy of $\pm 0.5^{\circ} \mathrm{C}$. The location of each of these thermocouples on the interior and exterior face of the specimen (glass lite and frame) follows that which is specified in standard CSA A440.2-04 as given in Figure 5. Thermocouples were also placed within the cavity between the window frame and window opening; the intent of placing thermocouples at these locations was to monitor the temperature in the space, and in proximity to the window frame, along the path of expected air leakage and through which cold air would migrate.

Figure 5 - Nominal location of thermocouples on exterior and interior face of test specimen 
In additional to continuous monitoring of surface temperature conditions, an IR camera was used to scan the surface temperature of the widow frame. The data was thereafter compared to that provided by the thermocouples. Acquiring an IR scan of the interior of the window requires the use of a baffle to minimize variations in surface conditions that may results from the presence of a camera operator in the warm side room.

Measurement of pressure differentials and airflow - Tests were carried out under a pressure differential that required the pressure difference across the test assembly to be continuously monitored during the test sequence. A pressure transducer having a $250 \mathrm{~Pa}$ range (1-in. water) and accuracy of $\pm 1 \mathrm{~Pa}$ was placed in the warm side chamber. Additionally, a pressure transducer was also used to monitor the pressure in the interstitial space between the window frame and the window rough opening in the wall. The requirement for a specified pressure differential across the test assembly necessitated the use of an air pump that expelled air from the warm side chamber. The amount of airflow was not monitored; however the flow was adjusted to accommodate the specified pressure differential.

\section{Experimental Procedures}

The basis for this test is observation of surface temperatures sufficient to cause the formation of condensation on window components located on the warm side of the test assembly. Actual visual observation of condensation is not required, nor desired, as the formation of condensation on thermocouples can affect measurements taken of affected sensors. Hence temperatures measurements on the warm side were undertaken in conditions where the humidity levels were sufficiently low to preclude the formation of condensation.

Calibration of test facility - The guarded hotbox test facility is calibrated according to the protocol described in Bowen [12] [1985]. The film heat transfer coefficient on the room-side and weather-side 
surfaces was determined from the calibration of the hot box with use of the Calibration Transfer Standard (CTS). For calibration, the CTS was mounted flush with the room-side surface of the surround panel.

Test procedure under no pressure differential - The tests in this instance were carried out without pressure differences across the specimen. The temperature differential for the initial test was set at $50^{\circ} \mathrm{C}$ $\pm 1.5^{\circ} \mathrm{C}$ and the temperature sensor measurements are recorded once steady state conditions have been achieved following a period of 15 minutes in these conditions $\left(20^{\circ} \mathrm{C}-\left(-30^{\circ} \mathrm{C}\right)=50^{\circ} \mathrm{C}\right)$. This test represents standard test conditions as described in CSA A440.2 [5]. The humidity on the warm side chamber was maintained at $5 \% \mathrm{RH}$ to ensure that no condensation occurred on any of the interior exposed surfaces of the widow frame. A time recorded scan using the Infra Red (IR) camera was taken for later analysis.

The test was repeated at a lower temperature differential of $45^{\circ} \mathrm{C}$ and thereafter at $40^{\circ} \mathrm{C}$ to investigate the extent to which such conditions altered the surface temperatures on the warm side of the window assembly. As was the case for the test conducted in standard conditions, temperature sensor measurements were recorded once steady state conditions had been achieved following a period of 15 minutes in these conditions and as well, the humidity on the warm side chamber was maintained at $5 \%$ RH to ensure that no condensation occurred. As before, a time recorded Infra Red (IR) camera scan was taken for subsequent analysis.

Test procedure when applying a pressure differential — The procedure for the test conducted under pressure differential first included incorporating deficiencies of specific type, size and location in the specimen as previously described. Once this had been completed, the prescribed temperature differential under no pressure differential was first attained and thereafter, differential pressure was slowly applied to the chamber by evacuating the warm side chamber to reach an initial pressure differential of $20 \mathrm{~Pa} \pm 0.5$ $\mathrm{Pa}$ and thereafter, a threshold of $40 \mathrm{~Pa} \pm 1 \mathrm{~Pa}$. The basis for this pressure threshold is the study conducted 
by Cornick [17] to establish hygrothermal test conditions for buildings located in northern Canada. The wind velocity pressure derived from an annual mean wind speed of $22 \mathrm{~km} / \mathrm{h}$ is $27 \mathrm{~Pa}\left(\right.$ at $\left.-30^{\circ} \mathrm{C}\right)$ [17]. Given that the calibration tests on the test setup described above revealed that 40Pa was the highest achievable pressure difference within reach of the test facility this was set as the possible upper threshold for the test pressure differential; measurements were also completed at 20Pa. The intent of taking measurements at two different pressure levels was to gain insight into the effect of varying pressure differences across the envelope on increasing the risk to the formation of condensation at the window. As was the case for the test conducted in standard conditions (i.e. at no pressure difference), temperature sensor measurements were recorded once steady state conditions had been achieved following a period of 15 minutes in these conditions.

\section{Numerical Simulation}

Steady state thermal simulations were done with the numerical software program BISCO 10.0w [9]. This program allows a simple conversion from CAD-based drawings into a user-defined grid size based on a triangulated grid model in conformity with EN ISO 10211 [11]. The system nodes are located at the triangle vertices, at which the temperatures are calculated and from which heat fluxes can be deducted. Material properties were adopted from EN ISO 10077-2 [19] and EN ISO 10456 [20]. Radiation is modeled iteratively in a non-linear way based on view factors (confined to 100 ray traces per cavity), whereas convection in cavities is calculated according to EN ISO 10077-2 [19]. The value for heat transfer coefficient at the weather side was $33.0 \mathrm{~W} / \mathrm{m}^{2} \cdot \mathrm{K}$, as measured in the hotbox. The heat transfer on the room side was calculated according to the formula $h_{c}=1.776 \cdot \Delta T^{0.25}[21]$. The surface temperature and heat transfer coefficients were calculated in 5 iterations (a uniform heat transfer coefficient was assumed). The black radiation heat transfer coefficient was set to $4.38 \mathrm{~W} / \mathrm{m}^{2} \mathrm{~K}$, and the grid size was $0.1 \mathrm{~mm}$. 


\section{Results}

\section{Test Set 4 (No Insulation)}

Without a pressure difference over the specimen there was a very homogeneous temperature distribution over the wall, window frame and glass on the outside (cold side) of the specimen $\left(-28.2{ }^{\circ} \mathrm{C}\right.$ to $\left.-29.1{ }^{\circ} \mathrm{C}\right)$. On the inside (warm side) of the specimen the temperature of the wall shows a little more variation, as could be expected; on the outside the air space between the WRB and the hardboard siding blocks any thermal bridging by wood studs to appear on the measurements. The temperature on the window frame and the insulated glass unit (IGU) has a strong thermal gradient; whereas the temperatures on the upper half of the window range from $11.9^{\circ} \mathrm{C}$ to $13^{\circ} \mathrm{C}$, temperatures between $4.1^{\circ} \mathrm{C}$ and $7.7^{\circ} \mathrm{C}$ are found near the sill. The argon inside the IGU-cavity will, when heated, rise towards the top of the unit, resulting in a typical thermal gradient; this is evident in Figure 6, in which is given an infrared photograph from the interior side of the test setup. Note that the convection in the interior cavity of the IGU would be even more pronounced in the case where it is filled with a gas with lower density, such as air. Figure 7 shows a picture from the window taken from the inside.

\section{Figure 6 - IR picture of test setup}

\section{Figure 7 - Picture inside view test setup}

As the cavity between the flanged window and the wood framing is approximately $12 \mathrm{~mm}(1 / 2 \mathrm{in})$ wide and $75 \mathrm{~mm}$ (3 in) deep, internal convection within the cavity might induce thermal stratification in the vertical air space, which is essentially open to the outside at the flange in front of the sub-sill. The cavity is located at the plane of thermal resistance of the window where the highest thermal gradient from inside to outside is evident, thus intensifying the resulting convection. Any cold air entering into the cavity will gather heat from the inner side of the window frame, and thereafter rise due to its descending mass density. However, due to this phenomenon one might expect a similar thermal gradient at the outside of the window - this was not observed. A possible explanation can be found by analyzing the window frame 
configuration. The specific design of the window profile lets the outside chamber partially act as a geometrical cooling fin, short-circuiting the location of the thermocouple. Furthermore, due to the high heat flux caused by the spacer of the insulated glass unit, the effect of other components on the temperature at the thermocouple is outclassed. A steady state simulation of the window-wall interface shows the temperature distribution in the interface in Figure $8\left(-30^{\circ} \mathrm{C}\right.$ to $\left.+20^{\circ} \mathrm{C}\right)$, and Figure 9 shows the

heat flux density $\left(0\right.$ to $200 \mathrm{~W} / \mathrm{m}^{2}$ ). A comparison of the simulation results and measurements are provided in Figure 10; the results show good correlation, except for the temperature in the cavity between window frame and wood stud wall (caused by convective effects in the window profile and in the cavity between frame and wall). However, an evaluation of static and dynamic simulation techniques does not lie within the scope of this paper and will be part of future research reports. Figure 9 shows the high heat flux through the spacer of the insulated glass unit, and next to that, the heat flux around the groove intensifies the thermal separation of that part of the frame from the cavity between frame and wall.

The data retrieved from the six thermocouples located in the cavity confirm a temperature gradient over the height of the cavity (Figure 11). However, when compared to the experiments with SPF in the cavity, in which both natural thermal stratification and forced air flow was eliminated, it seems that a part of the observed temperature gradient is caused by other effects. The mounting brackets were not close enough to the thermocouples to affect the measurement, and given that this was a non-operable window, hence without hinges or stays, it is apparent that neither of these items can affect results. The vertical thermal gradient in the cavity is monitored throughout all measurements and is consistent in nature.

Figure 8 - Simulation section: isothermal lines Figure 9-Simulation section: heat flux intensity

Figure 10 - Validation of steady-state simulation 
The thermocouples are mounted onto the vinyl frame, so perhaps the window frame itself can account for the measured effects. The cross section of the window frame reveals that the section is comprised of two large cavities; the thermocouples are attached to the exterior surface of the largest cavity, but closer to the interior side of the assembly. Experimental analysis and numerical modeling of convection in a tubular one-inch square vinyl frame has been previously discussed by Gustavson et al. [22]. In this work, it was evident that for a temperature difference of $20^{\circ} \mathrm{C}$ over a vertical tube of length $800 \mathrm{~mm}$ (forming part of a $800 \mathrm{~mm}$ by $800 \mathrm{~mm}$ vinyl frame) there was a vertical thermal gradient of about $2^{\circ} \mathrm{C}$, excluding conductive effects at top and bottom of the tube. Whereas in the test set-up to assess condensation risk of interest in the present study, the temperature difference is $50^{\circ} \mathrm{C}$, and it is most likely that a large part of that will act over the vertical window frame cavity because it is located at the plane of highest thermal resistance of the IGU and the wall. Although this cavity is smaller than that evaluated from Gustavson's work (about half the size), and results possibly compensated by a larger temperature difference, this is the most plausible explanation to account for the observed thermal gradient along the vertical axis of the window frame.

Condensation risk assessment - With regards to assessing the risk to the formation of condensation, differentiation can be made between surface condensation at any visible location and interstitial condensation inside the cavities between the different components. As cold air passes through the interior construction, it will not only cool the adjacent components, but also dry the air (vapour pressure remains constant, but the RH is diminished as the air gets warmer). This effect will not be present at the interior visible surface, as the air might enter the room at a different location. However, one should take into account that pressure differences over building envelopes are induced by a set of causes. Wind loads, stack effects and HVAC systems might be able to change the pressure any time and reverse the air flow through deficiencies. Obviously this situation would increase the risk to condensation inside the assembly itself, which in principle should be avoided any time. It may be assumed that long-lasting pressure differences (sufficiently long to cool the adjacent components) are not sequenced by opposite long-lasting 
static pressure differences. Such a situation is only likely to occur due to malfunctioning HVAC-systems. Hence, only the risk to the formation of surface condensation is considered in this paper.

In this respect, the risk to the formation of condensation depends only on two parameters (assuming constant pressure conditions): temperature and humidity. For any given surface temperature there can be condensation if the humidity is sufficiently high. A practical approach to analyze the data is to calculate the dimensionless temperature index for every test case. This index value provides normalized results and thus an objective basis of comparison of results derived from testing the different setups. Furthermore, given that heat transfer is linearly correlated with temperature difference, this index is independent of the specific temperatures used in the experiments. For any boundary conditions, the indoor surface temperature can be calculated using the temperature index. A straightforward psychometric calculation offers the maximum relative humidity for the specific indoor temperature in order to avoid surface condensation on the window frame.

Figure 11 shows an overview of the different temperatures on the insulated glass unit, the window frame and the cavity between the window frame and the wall. The circles on the wall show the locations of the different thermocouples on the surface, e.g. to check if no thermal stratification would occur in the test chamber (for reasons of clarity these are not reported here). The locations of the different thermocouples on the glass and frame are marked, and corresponding temperatures are shown in result boxes. In every result box the top value refers to the situation without a pressure difference over the wall, the middle number was measured at $20 \mathrm{~Pa}$, and the bottom value corresponds to $40 \mathrm{~Pa}$ pressure difference. On the upper half of the window frame, the temperature is $11.9^{\circ} \mathrm{C}$, temperature index 0.85 (without pressure difference) (Figure 11 and 12), down at the window sill temperatures are lower and the corresponding temperature and index are $4.1^{\circ} \mathrm{C}$ and 0.69 respectively. The temperature index is rounded at two digits, which corresponds to a rounding of the temperature to $0.5^{\circ} \mathrm{C}$. For a temperature difference of $50^{\circ} \mathrm{C}(-$ $30^{\circ} \mathrm{C}$ to $\left.+20^{\circ} \mathrm{C}\right)$, the surface temperature is $\left(0.69 * 50^{\circ} \mathrm{C}\right)-30^{\circ} \mathrm{C}=4.5^{\circ} \mathrm{C}$. The difference between the 
$4.5^{\circ} \mathrm{C}$ and $4.1^{\circ} \mathrm{C}$ is caused by a deviation of the indoor temperature (was slightly lower than the $20^{\circ} \mathrm{C}$ set

point). As such, the temperature index is a more reliable measure to compare results and is independent of the boundary conditions of the experimental test setup. For other boundary conditions the surface temperature can similarly be calculated, offering a comprehensive method to calculate condensation risk for a specific indoor condition. The component of the window frame that consistently permitted establishing the risk to the formation of condensation was the lower part of the window frame. Hence, for reasons of clarity, only results for the lower portion of the window frame and insulating glass unit at the sill will be reported. Merely for illustration, according to this calculation the temperature index in the cavity between window frame and wood framing would be 0.55 .

\section{Figure 11 - Temperatures on the frame and inside the cavity for different pressure differences.}

Effect of pressure differences (no deficiencies) - In order to analyze the effect of cold air infiltrating into the construction, a pressure difference of 20 and 40Pa was applied. Due to this unbalance, cold air was drawn into the warm side of the assembly through small cracks and openings in the different components of the specimen. As there were no wilful deficiencies in the initial test (i.e. purposely incorporated deficiencies not functional in this set-up), air could only enter through local imperfections of the wall, window-wall interface or window frame. The results from the tests indicate that the temperature distribution is very similar to the test without pressure difference (taking into account a slightly lower room temperature). However, a lower temperature inside the cavity at the corners of the window was noted. Already divergent from the general trend in the first measurement, this becomes more pronounced as the pressure difference is increased. Although this effect may partially be explained by the threedimensional heat transport in the corners of the window frame (introducing a point thermal bridge), that should only be proportional to the temperature difference, which is clearly not the case here. A close examination of several samples of the window used in this study revealed specific imperfections at the 
mitred joint of the heat welded vinyl frame. The mitred joint was chamfered after welding, but in some instances was apparently cut off, thereby revealing a small opening (slit) at the exterior corners of the window frame. On the other hand, at the top and bottom side of the window there were minor perforations caused by staples that held the wood protection strapping in place during transport. As well and contrary to good practice, there were no weep holes at the bottom side of the window. It may be stated that the windows used in this study were of low quality and additionally were obtained having several deficiencies present specifically at the corners both on the inside and outside of the frame. These rendered it possible for cold air to enter the window frame at any openings on the outside of the frame between the WRB and cladding (blocking the effect from the thermocouple measurements), and the air could then exit the frame at exterior corners, in the cavity behind the sealed window flanges. Tests with smoke pencils and IR photographs of the window exclude any unintended deficiencies to be the cause. Perhaps there were some cracks or slits at the perimeter of the wall specimen mounted in the hot-box. A laminar flow of air between the air barrier and the drywall could remain undetected, allowing the air to exit the cavity. As will be explained in the analysis of the test setup with fiberglass insulation in the cavity, this will affect the temperatures in the overall cavity as well.

When a $20 \mathrm{~Pa}$ (or $40 \mathrm{~Pa}$ ) pressure was applied, the temperature on the window frame decreased by $0.8^{\circ} \mathrm{C}$ $\left(0.9^{\circ} \mathrm{C}\right)$ at the top side and $1.4^{\circ} \mathrm{C}\left(1.8^{\circ} \mathrm{C}\right)$ at the bottom side of the window frame. Although the pressure difference is doubled, one should take into account the power law in respect to the air leakage rate, specifically:

$$
Q=C \cdot \Delta p^{n}
$$

With Q: air flow rate [L/s], C: flow coefficient [L/s.Pa $\left.{ }^{n}\right]$, n: flow coefficient [-]. It can reasonably be assumed that the flow exponent of the specific deficiency lies between 0.55 and 0.65 for building applications. Within this range of flow exponents the air flow would rise between $46 \%$ to $57 \%$ when the 
pressure difference is doubled. Hence, the temperature drop cannot be expected to be directly proportional to the pressure difference. Based on the pressure difference, discharge coefficient of the deficiencies and internal friction it is possible to estimate effective airflow rates. Any assumed velocity profile inside the cavity will affect the convective heat transfer coefficient at the boundary layer with the window profile. However, this analysis requires a more elaborate fundamental study which is beyond the scope of this study but may be investigated in future research.

With regards to the condensation potential, the results are similar to the tests without pressure difference: a temperature index of 0.69 at $0 \mathrm{~Pa}, 0.66$ at $20 \mathrm{~Pa}$ and 0.66 at $40 \mathrm{~Pa}$. The low temperatures in the cavity would cause severe problems during a rapid change of air flow direction: a temperature of $-8^{\circ} \mathrm{C}$ corresponds to a temperature index of 0.44 , so humid indoor air could easily condense on that surface.

Effect of deficiencies - During the second series of tests two deficiencies were installed: one at the lower right corner on the outside (D1) and one on the upper left corner on the inside (when looking from the inside of the window - D3). When no pressure difference is applied, results are identical to the previous test. The temperature in the cavity exactly at the deficiency on the outside drops $3^{\circ} \mathrm{C}$; however, other than this result no differences are recorded. Due to the big temperature difference between the inside and the outside there is a difference in mass density of the air. Any direct contact between both spaced through an opening will result in a local stratification, pressure difference and air exchange. The local temperature drop can be traced back to the deficiency connecting the cavity to the outside. As one looks at the other deficiency (D3), a similar effect is not found. First of all, the temperature difference between the cavity and the outside at the lower deficiency(D1) is about $30^{\circ} \mathrm{C}$, whereas the temperature difference at the top corner is only $14^{\circ} \mathrm{C}$ (cfr. the temperature stratification in the vertical section of the cavity). As well, the deficiency at the lower side (D1) is close to the slit between the flange and WRB, offering limited resistance to air flow. Measurements confirm that the pressure difference recorded at the bottom $(0.5 \mathrm{~Pa})$ 
is lower than the pressure difference at the top $(1.3 \mathrm{~Pa})$; note as well that there is no vertical temperature gradient in both rooms, only in the cavity itself.

Effect of deficiencies and pressure differences - When a pressure difference of 20Pa is applied whilst deficiencies are present (see Figure 12), the outside surface temperatures remain the same, but the surface temperature of the window profile on the inside goes down about $1.5^{\circ} \mathrm{C}$ compared to the test without deficiencies (about $2^{\circ} \mathrm{C}$ for $40 \mathrm{~Pa}$ ). A temperature drop of $1^{\circ} \mathrm{C}$ corresponds to a drop of 0.02 points in the temperature index (for the given boundary conditions of the test setup). Compared to the test with the deficiencies active but no pressure difference, the upper part of the window cools down slightly less than $1^{\circ} \mathrm{C}$ at $20 \mathrm{~Pa}$ and the lower part $2^{\circ} \mathrm{C}$; at $40 \mathrm{~Pa}$ the corresponding values are $1^{\circ} \mathrm{C}$ and $3^{\circ} \mathrm{C}$ respectively. In the cavity the effect is most pronounced in the corners. At $20 \mathrm{~Pa}$ the temperature drops $1.5^{\circ} \mathrm{C}$ and $3^{\circ} \mathrm{C}$ at the bottom corners and $7^{\circ} \mathrm{C}$ at the top left corner. A temperature drop of $2.5^{\circ} \mathrm{C}, 6^{\circ} \mathrm{C}$ and $13.5^{\circ} \mathrm{C}$ respectively were measured inside the cavity at $40 \mathrm{~Pa}$. The results permit suggesting that a constant pressure difference of $40 \mathrm{~Pa}$ has a significant effect on the indoor surface temperatures, but is limited to about $3^{\circ} \mathrm{C}$ (the temperature index drops, at most, 0.08). The surface temperatures at the inside of the window will decrease somewhat, imposing a temperature index of $0.66(0.63)$ at the bottom half of the window at 20Pa (40Pa). The initial temperature index for a window without deficiencies nor pressure differences was 0.69. As could be expected the effect was more pronounced in the cavity near the corners resulting in temperatures as low as $-7.3^{\circ} \mathrm{C}\left(-11.4^{\circ} \mathrm{C}\right)$ at $20 \mathrm{~Pa}(40 \mathrm{~Pa})$, corresponding to temperature indexes of 0.45 (0.38).

\section{Figure 12 - Temperature indexes when deficiencies are present.}

\section{Test Set 5 (Fiberglass Insulation)}

For this test setup the cavity between the window frame and the wood framing was filled with fiberglass insulation and caulked on the interior side. The surface temperatures on the outer side do not differ from 
those obtained in the test set-up without insulation (Test Set 4). On the inside, the effect is most pronounced for the surface temperature of the window frame, which is consistently $0.5^{\circ} \mathrm{C}$ to $1{ }^{\circ} \mathrm{C}$ higher due to the insulation. However, this is not the case for the IGU, whereby the temperature index stays at 0.69. In fact the surface temperature of the glass perimeter is primarily determined by the centre-of-panel R-value of the IGU, the IGU-spacer along the edges, and the removable glazing stop of the window frame. Indeed the effect on the IGU will be negligible given the limited lateral thermal resistance of the frame and unless the temperature around the frame is below a certain threshold. The cavity between the window and the window rough opening, now filled with insulation, is about $0^{\circ} \mathrm{C}$ to $2^{\circ} \mathrm{C}$ warmer compared to the setup without insulation. It should be noted that there is still a minor thermal gradient present, albeit less pronounced then earlier. This confirms the findings concerning the effect of convection inside the vertical mullions of the window frame. A detailed analysis of the results indicates that the calculated thermal gradient is smaller than the one observed without insulation, but slightly larger than the one observed with SPF insulation. Either this is caused by thermal stratification (despite the resistance of the fiberglass insulation), or there is an upward air flow caused by a leak. In the latter case, it would also account for a part of the thermal gradient in the setup without insulation. In the horizontal cavity at the sill the temperature is significantly higher than the test without insulation, consistent with the assumed convection effects.

Effect of pressure differences - Both for 20 and 40Pa there is no important effect on the outdoor surface temperatures, not for the wall, not for the window frame, and not for the IGU. The window frame temperature on the inside diminishes by $1.2^{\circ} \mathrm{C}$ at $20 \mathrm{~Pa}$ and $2.1^{\circ} \mathrm{C}$ at $40 \mathrm{~Pa}$. In the cavity between the window frame and the window rough opening, the temperature drop is the same as an assembly without insulation. Without insulation the average temperature drop in the vertical cavity due to a 40Pa pressure difference was $0.8^{\circ} \mathrm{C}$, and with insulation it was $0.6^{\circ} \mathrm{C}$. The resistance of the fiberglass insulation to air flow can account for this small change. However, an explanation for temperature variations at the corners differs from that provided above; whereas the upper left corner responds in a similar fashion to the case 
without insulation, the two bottom corners get extremely cold during this test. At 20Pa these cool to $7.3^{\circ} \mathrm{C}$ and $-6.5^{\circ} \mathrm{C}$ (compared to $-3.5^{\circ} \mathrm{C}$ and $-3.1^{\circ} \mathrm{C}$ without insulation), and at $40 \mathrm{~Pa}$ even to $-11.2^{\circ} \mathrm{C}$ and $11.4^{\circ} \mathrm{C}$ (compared to $-5.4^{\circ} \mathrm{C}$ and $-4.0^{\circ} \mathrm{C}$ ). One would assume that the fiberglass insulation would reduce the flow of air through the cavity, and the corresponding temperature drop should hence be lower. During this test the 5 thermocouples on the lower side of the drywall register an average temperature drop of $0.9^{\circ} \mathrm{C}$, whereas the room side temperature is exactly the same. There must have been a local deficiency in the caulking along the sill, through which the cold air could flow at much higher flow rates, in between the drywall and the air barrier towards any deficiencies in the wall installation perimeter.

Effect of deficiencies - The results of the test with the two deficiencies (D1 and D3) in the construction show a general temperature rise of $0.2^{\circ} \mathrm{C}$, which can be attributed to measurement errors and rounding errors. Without batting there was a temperature drop at one deficiency of $3^{\circ} \mathrm{C}$. Even near the deficiencies no temperature drop is recorded in this test. The fiberglass insulation blocked some movement of air and as well, may have insulated the thermocouple from what was occurring at the middle of the cavity. However, this should only have dampened the effect, not caused it to disappear. As mentioned before, the window frames were found to be of low quality with several deficiencies near the corners; it may be possible that a deficiency causing the temperature drop in the previous case became neutralized due to the caulking that was redone after the insulation was installed. Nonetheless, there is no effect on the condensation risk.

Effect of deficiencies and pressure differences - Whilst there is no effect on the outside surface temperatures, a pressure difference has a distinct effect on the window frame temperatures on the inside. Figure 13 shows the temperature indexes for the case where deficiencies are present and a pressure difference of $40 \mathrm{~Pa}$ is applied across the test specimen. The results, provided from top to bottom, include respectively, the test without insulation between window frame and wall, with fiberglass insulation and with SPF. Along the path running from the outside deficiency in the lower right corner to the deficiency 
on the inside top left corner the temperatures on the window profile decrease from about $2{ }^{\circ} \mathrm{C}$ to $3.5^{\circ} \mathrm{C}$ at $20 \mathrm{~Pa}$ and $2.5^{\circ} \mathrm{C}$ to $4.5^{\circ} \mathrm{C}$ at $40 \mathrm{~Pa}$. During the test without insulation the effect of air leakage across the window frame at $40 \mathrm{~Pa}$ was less pronounced and was limited to $1^{\circ} \mathrm{C}$ to $3^{\circ} \mathrm{C}$. Thus contrary to expectations, higher flow rates caused lower temperatures, despite the fact that fiberglass insulation was present and should reduce air movement. This can only be caused by uncertainties in the experimental set-up, such as small cracks or other deficiencies. Figure 13 shows the lowest temperature indexes inside the cavity for the case with fiberglass insulation in the cavity. The effect on the temperature index at the interior surface is negligible. Although it may not be clear what causes the higher air flow rates, it is established that air leakage around the window perimeter can considerably lower the window surface temperature. Peak values of temperature shift between test pressure conditions are $3.3^{\circ} \mathrm{C}$ and $5.4^{\circ} \mathrm{C}$ for $20 \mathrm{~Pa}$ and $40 \mathrm{~Pa}$ respectively. The temperature index during a pressure difference of $40 \mathrm{~Pa}$ is 0.63 . This is very similar to the earlier results when there is no insulation in the cavity. However, note that the temperature index for an installation without insulation, without deficiencies, and without pressure differences, was just slightly higher: 0.69. Even though a static pressure difference of 40Pa is quite high and not likely to occur, the effect on the indoor surface temperatures is about $10 \%$ of the overall applied temperature difference.

\section{Figure 13 - Temperature indexes at 40Pa with deficiencies for the different test sets.}

\section{Test Set 6 (Spray Polyurethane Foam)}

The application of spray-in-place polyurethane foam (SPF) inside the cavity should prevent any convection to occur. The surface temperatures are similar to the case with fiberglass insulation and thus the same hygrothermal criteria apply. The thermal gradient along the vertical axis in the cavity between window and window rough opening is slightly lower than in the previous cases. The SPF blocks all convection in that cavity, but there still remains thermal stratification inside the window profiles as was discussed previously. 
Effect of deficiencies and pressure differences - Although there may be no convection in the cavity, a pressure difference of $20 \mathrm{~Pa}$ allowed a reduction in the surface temperature of the window profile, on average, of $1.2^{\circ} \mathrm{C}$, and for $40 \mathrm{~Pa}$, this reached $2.3^{\circ} \mathrm{C}$. Again, in absence of thermal effects in the cavity around the window, the cause of this temperature drop lies within the window frame itself. Only deficiencies in the window could permit an airflow that affects the surface temperature at that location. The temperature drop was very similar to the case with fiberglass insulation. At $40 \mathrm{~Pa}$ the temperature drop was more pronounced in the case of the SPF insulated window. As SPF generally insulates better than fiberglass, the cold air can extract less heat from the cavity around the window, causing a greater heat flux towards the inside through the window frame. This confirms the general principle that a thermal bridge can be accentuated by insulating the surrounding components. The temperature index was 0.67 and 0.65 for $20 \mathrm{~Pa}$ and $40 \mathrm{~Pa}$ respectively. Deficiencies caused no change in the temperature profile with or without pressure difference. The SPF blocked any possible air flow around the cavity; hence pressure differences have no influence on surface temperatures.

\section{Concluding Remarks}

A test protocol has been developed to determine the condensation potential of windows based on existing CSA A440.2 test standard but that also included a means to determine the effects of air leakage on the risk to condensation on windows. The windows were installed in a 2-ft. by 4-ft. opening of a 2-in. by 6-in. wood frame assembly, the assembly being typical of cold climate North American construction practice. The installation details were those that promote the management of rainwater entry and incorporate such features as sloped sill, sill pan flashing membrane, and back dam. Air leakage across the wall-window interface may increase the likelihood that condensation may form on the window. Hence, deficiencies simulating either the improper installation of components or the premature failure of critical seals have been included in the evaluation to verify the degree to which such openings influence the risk to condensation. The risk to condensation was first determined in conditions where no deficiencies were 
present at the wall-window interface and thereafter, a series of defects were included that permitted air, in varying degrees, to penetrate the interface. In each instance, the surface temperatures of the window were monitored to establish any changes in comparison with the instance where no defects were present. This series of experiments were first conducted with no insulation in the cavity between the window unit and the window rough opening and thereafter with fiberglass batt insulation and spray-in-place polyurethane foam. This permitted comparing the relative importance of insulating the cavity on the performance in regard to the risk to condensation of these approaches to window installation practice. The information developed from these tests provides guidance to window manufacturers, window installers and knowledgeable practitioners investigating window deficiencies, and the effects of such deficiencies on thermal performance at windows.

The experimental results for determining the condensation potential of flanged windows when installed in a wood frame wall assembly are reported in this study. The following observations and analysis were made through the set of experiments carried out in this study:

- The exterior side of the configuration was not sensitive to thermal effects induced by air leakage to the inside. This means that, e.g., the use of IR-scans may not be useful for visualizing convective effects in the window-wall interface from the outside.

- The temperatures on the insulated glass unit showed a significant vertical thermal gradient, and the spacer around the perimeter acted as an additional thermal bridge causing low surface temperatures in all configurations. However, the IGU was not sensitive to the response that occurred inside the cavity between the window frame and the rough opening.

- The flanged window used in the measurements was of lesser quality, as several cracks and deficiencies in the window frame, in certain instances, directly affected results. Even for the installation with SPF without deficiencies it was observed that the surface temperature on the window profile dropped $2.3^{\circ} \mathrm{C}$, possibly caused by insufficient airtightness of the window frame. 
- Due to air flows around the window there was a temperature drop up to $3.3^{\circ} \mathrm{C}(20 \mathrm{~Pa})$ and $5.4^{\circ} \mathrm{C}$ (40Pa) on the interior window profile. This corresponds to a change in temperature index of 0.07 and 0.11 respectively. As mentioned, half of this can be attributed to the low performance window. It appears that the effect of cold air flow and air leakage through the window frame have the same order of magnitude.

- As the window installation was tested under severe conditions $\left(50^{\circ} \mathrm{C}\right.$ and $40 \mathrm{~Pa}$ difference between interior and exterior climate), the overall effect of air flows is rather limited. However, these results are only valid for the vinyl frame window used in this study.

- Convective air transport around the window was not sufficiently retarded by the installation of fiberglass insulation. Only the use of spray polyurethane foam insulation correctly provided a seal to the perimeter thereby avoiding cooling the window profile.

- This paper reports experimental results for window-wall interfaces with flanged windows; results on box windows will be analyzed and reported in a subsequent publication.

- Future research will focus on the validation of dynamic simulation tools and convective heat transfer coefficients to assess the condensation risk for different interfaces. Based on the experimental data and dynamic simulations comprehensive design guidelines will be published to assess the condensation risk based on outdoor temperature, indoor temperature and internal moisture loads.

\section{Acknowledgements}

The authors wish to thank the Canada Mortgage and Housing Corporation for partial funding of the project and acknowledge the contributions of Mr. Silvio Plescia, Senior Researcher, Canada Mortgage and Housing Corporation to this paper.

\section{References}

1. Sasaki, J.R. (1971), "Developing a standard test for window condensation performance," Materials Research and Standards, 11, (10), pp. 17-20, October, 1971 (NRCC-11847) (DBR-RP-473) 
2. AAMA (1972), Architectural Aluminium Manufacturers Association, "Voluntary Test Method for Condensation Resistance of Windows, Doors and Glazed Window Sections," Publication No. AAMA 1502.3-1972, 1972.

3. AAMA (1998), Architectural Aluminium Manufacturers Association, "Voluntary Test Method for Thermal Transmittance and Condensation Resistance of Windows, Doors and Glazed Wall Sections", Publication No. AAMA 1503-98

4. ASTM (2000), ASTM C1199-00 "Standard Test Method for Measuring the Steady-State Thermal Transmittance of Fenestration Systems Using Hot Box Methods”, ASTM Book of Standards, Vol. 04.06, ASTM Publications, PA, USA, 19 p.

5. CSA (2004), Energy performance of windows and other fenestration systems/User guide to CSA A440.2-04, Energy performance of windows and other fenestration systems, Canadian Standards Association, Mississauga, Ontario, August, 108 p.

6. Elmahdy, A.H. (1990), A Universal approach to laboratory assessment of the condensation potential of windows, Sustainable Energy Choices for the 90's : 16th Annual Conference of the Solar Energy Society of Canada, Halifax, N.S., Canada, pp. 165-173.

7. Enermodal Engineering (1996), FRAME, A Computer Program to Evaluate the Thermal Performance of Window Frame Systems, Version 4.0. Developed for CANMET, Division of Natural Resources Canada. Enermodal Engineering Limited.

8. University of Waterloo (1996), VISION 4.0, Glazing System Thermal Analysis: User's and Reference Manual, University of Waterloo Advanced Glazing System Laboratory.

9. Physibel (2009), BISCO 10.0w computer program to calculate two-dimensional steady state heat transfer in free-form objects, Adegem, Belgium.

10. McGowan, A.G. and Wright, J. L. (1998), Computer simulation of window condensation potential, Proceedings of "Thermal performance of the exterior envelopes of buildings VII", (Sheraton Sand 
Key Hotel, Clearwater Beach, FL), American Society of Heating, Refrigerating and Air Conditioning Engineers (ASHRAE), Atlanta.

11. EN ISO 10211 (2007), Thermal bridges in building construction - heat flows and surface temperatures - Detailed calculations. CEN, Brussels, Belgium.

12. EN ISO 13788:2001 (2001), Hygrothermal performance of building components and building elements -- Internal surface temperature to avoid critical surface humidity and interstitial condensation -- Calculation methods, ISO, Geneva, Switzerland

13. Elmahdy, A.H. and Bowen, R.P. (1988), Laboratory determination of the thermal resistance of glazing units, ASHRAE Transactions 94 (2): pp. 1301-1316

14. Brown, W.P., Solvason, K. R. and Wilson, A.G. (1961), A unique hot-box cold-room facility. ASHRAE Trans., V. 67, 1961, pp. 561-577

15. Lacasse, M.A.; Manning, M.M.; Rousseau, M.Z.; Cornick, S.M.; Plescia, S.; Nicholls, M.; Nunes, S.C. (2007), "Results on assessing the effectiveness of wall-window interface details to manage rainwater," 11th Canadian Building Science and Technology Conference (Banff, Alberta, March 22, 2007), pp. 1-14, March 22, 2007 (NRCC-49201)

16. Lacasse, M.A.; Rousseau, M.Z.; Cornick, S.M.; Plescia, S. (2005), "Assessing the effectiveness of wall-window interface details to manage rainwater," 10th Canadian Conference on Building Science \& Technology (10BS\&T) (Ottawa, ON, May 12, 2005), pp. 127-138, May 01, 2005 (NRCC-47685)

17. Cornick, S.M. (2008), Task 5: Proposed Test Protocol for Walls of Houses in Extreme Cold Regions. Part 1: Defining Exterior Conditions, pp. 47, (B-1239.5)

18. ASCE/SEI 7-05 (2005), Minimum Design Loads for Buildings and Other Structures, Structural Engineering Institute of the American Society of Civil Engineers, US.

19. EN ISO 10077-2 (2003), Thermal performance of windows, doors and shutters - calculation of thermal transmittance - Part 2: numerical method for frames. CEN, Brussels, Belgium. 
20. EN ISO 10456 (2008), Building materials and products - hygrothermal properties - tabulated design values and procedures for determining declared and design thermal values. CEN, Brussels, Belgium.

21. Khalifa, A-J. N. (2001), Natural convective heat transfer coefficient - a review. 1. Isolated vertical and horizontal surfaces. Energy conversion and management 42: 491-504.

22. Gustavson, A., Griffith, B.T. and Arasteh, D. (2001), Three-Dimensional Conjugate Computational Fluid Dynamics Simulations of Internal Window Frame Cavities Validated Using Infrared Thermography, ASHRAE Transactions, Vol. 107, Pt 2. 
Please thermal resistance window

Plane thermal resistance wall 


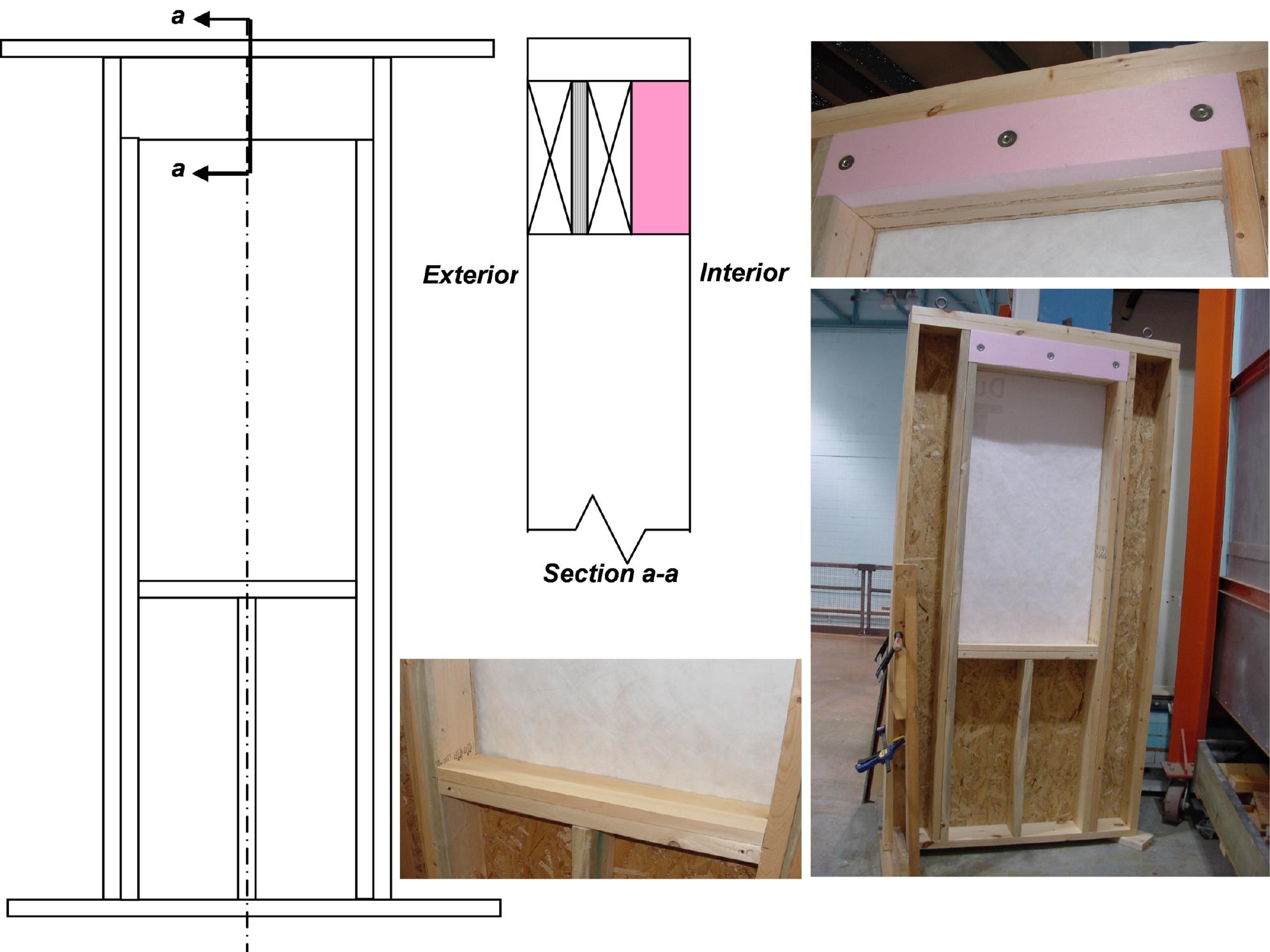




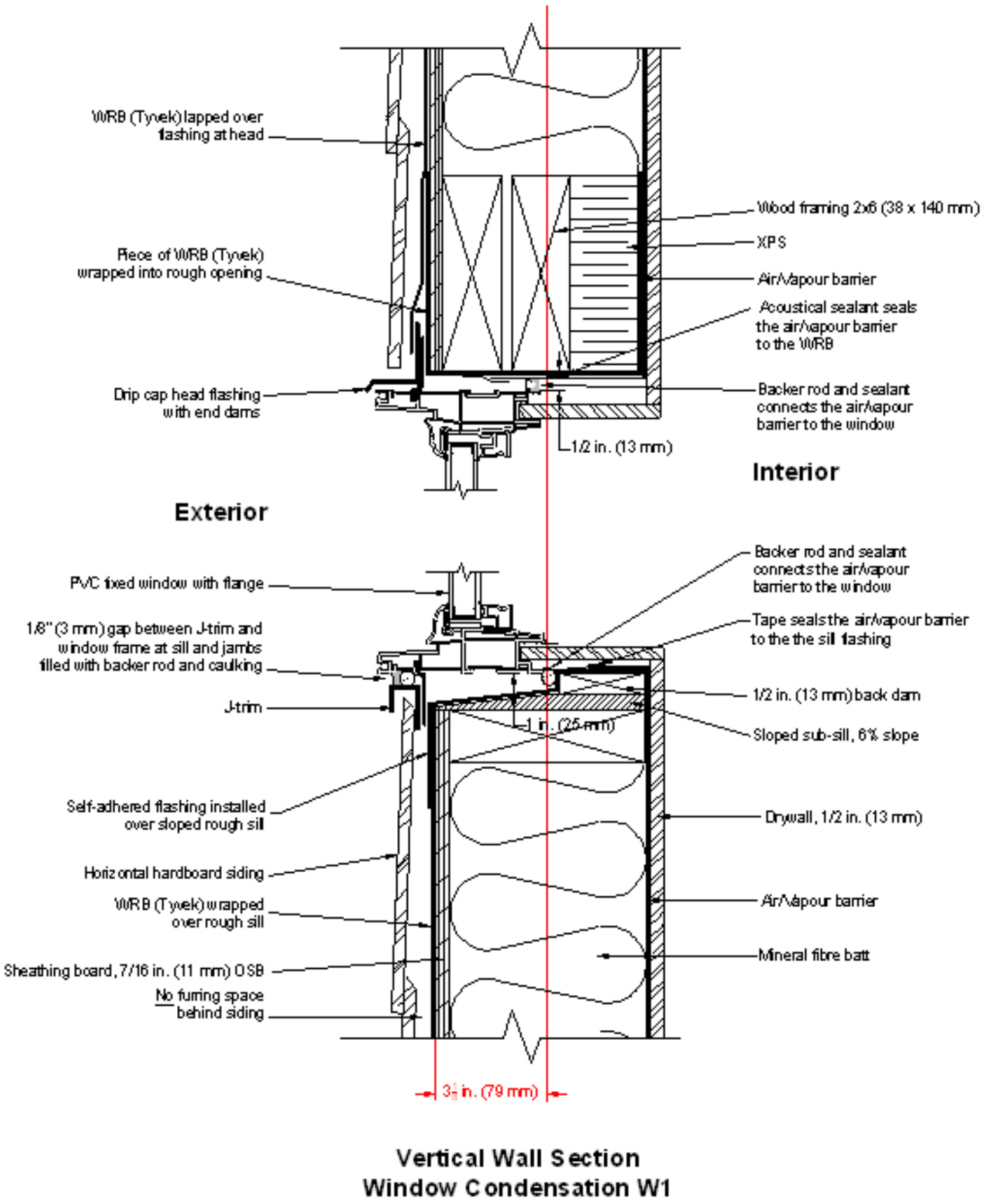




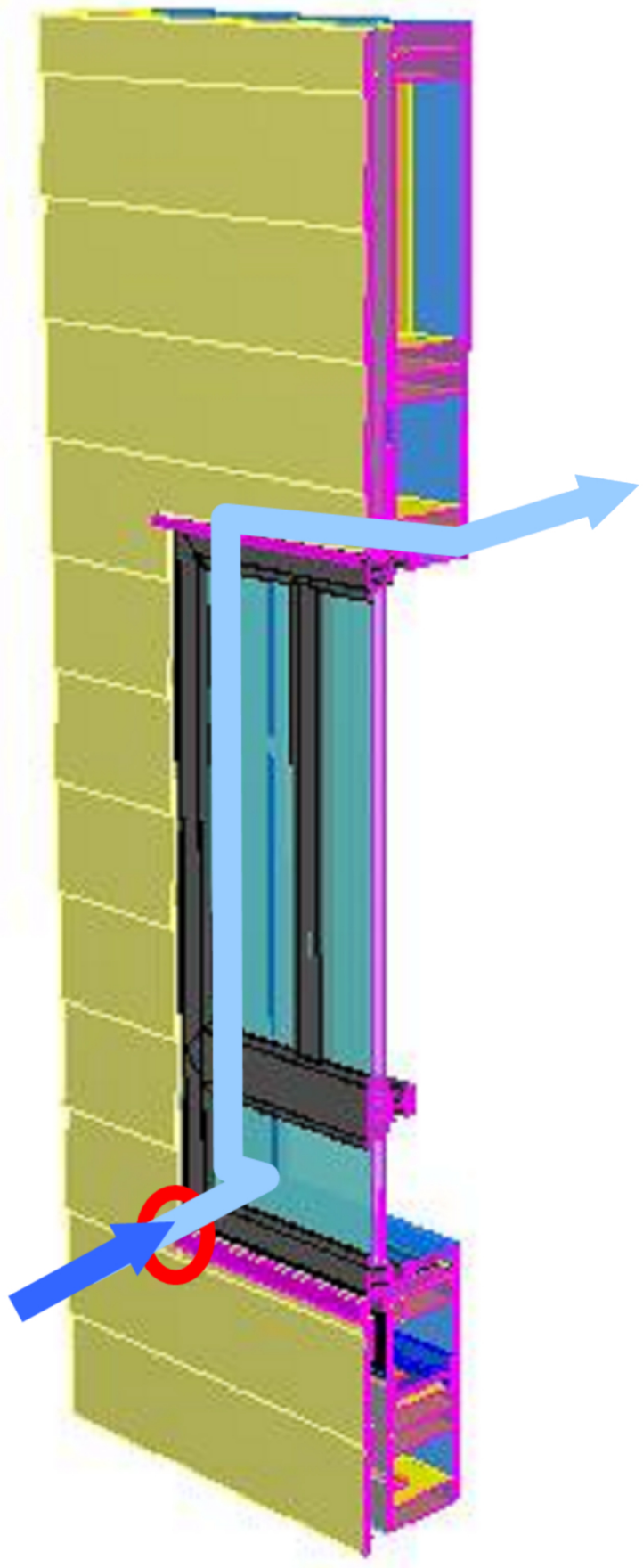




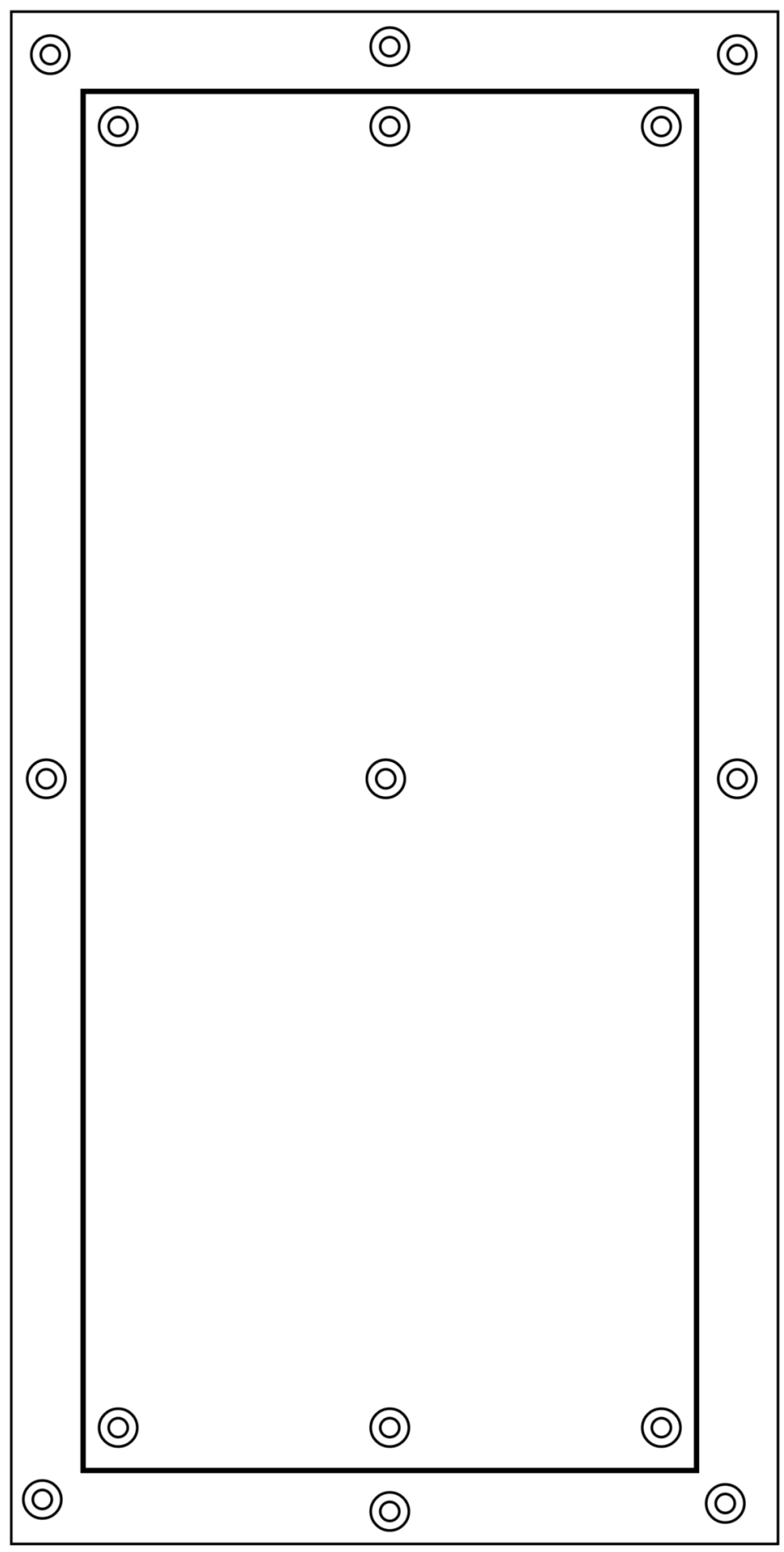



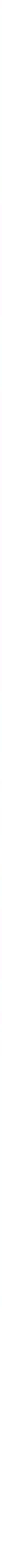


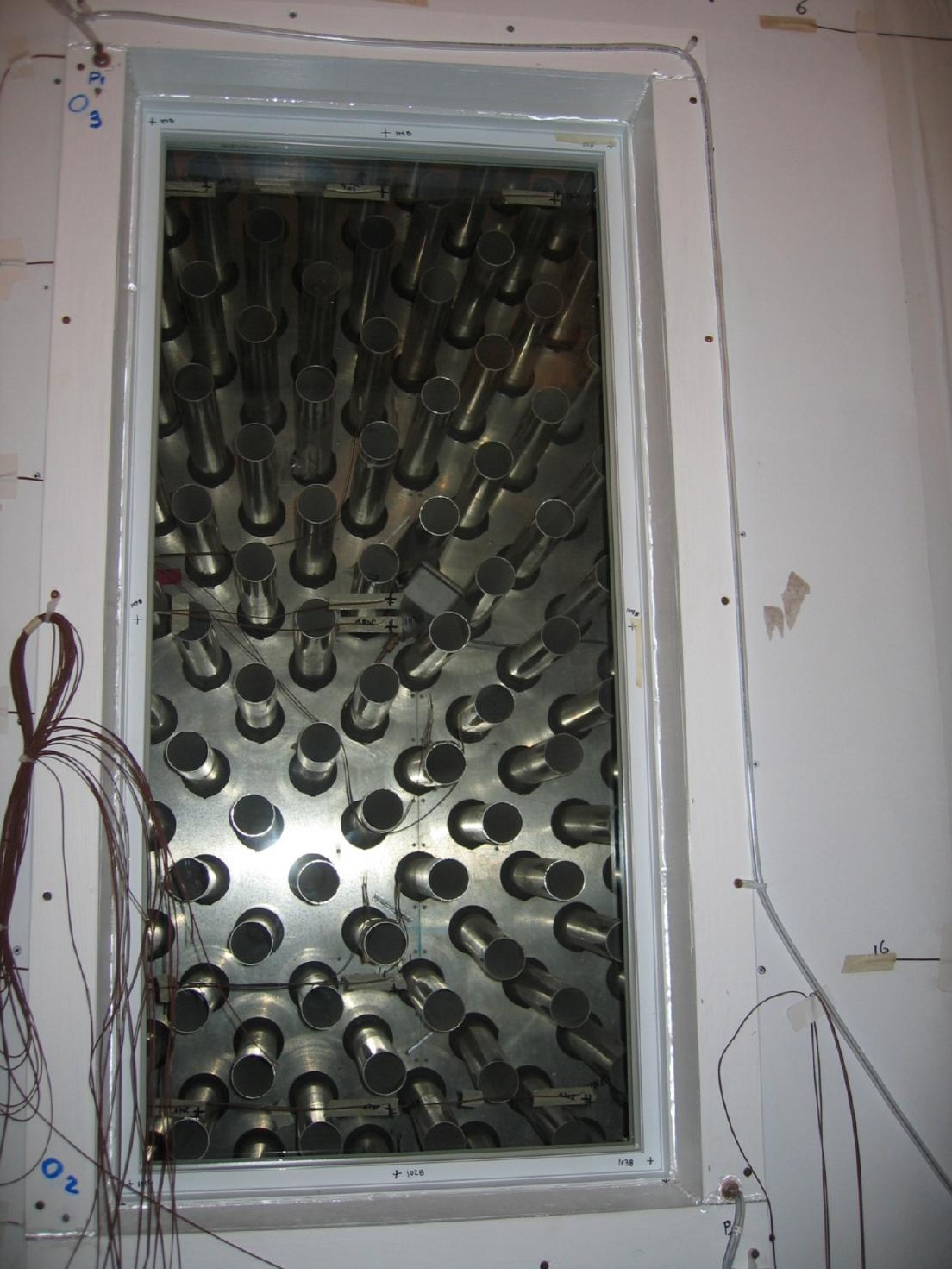




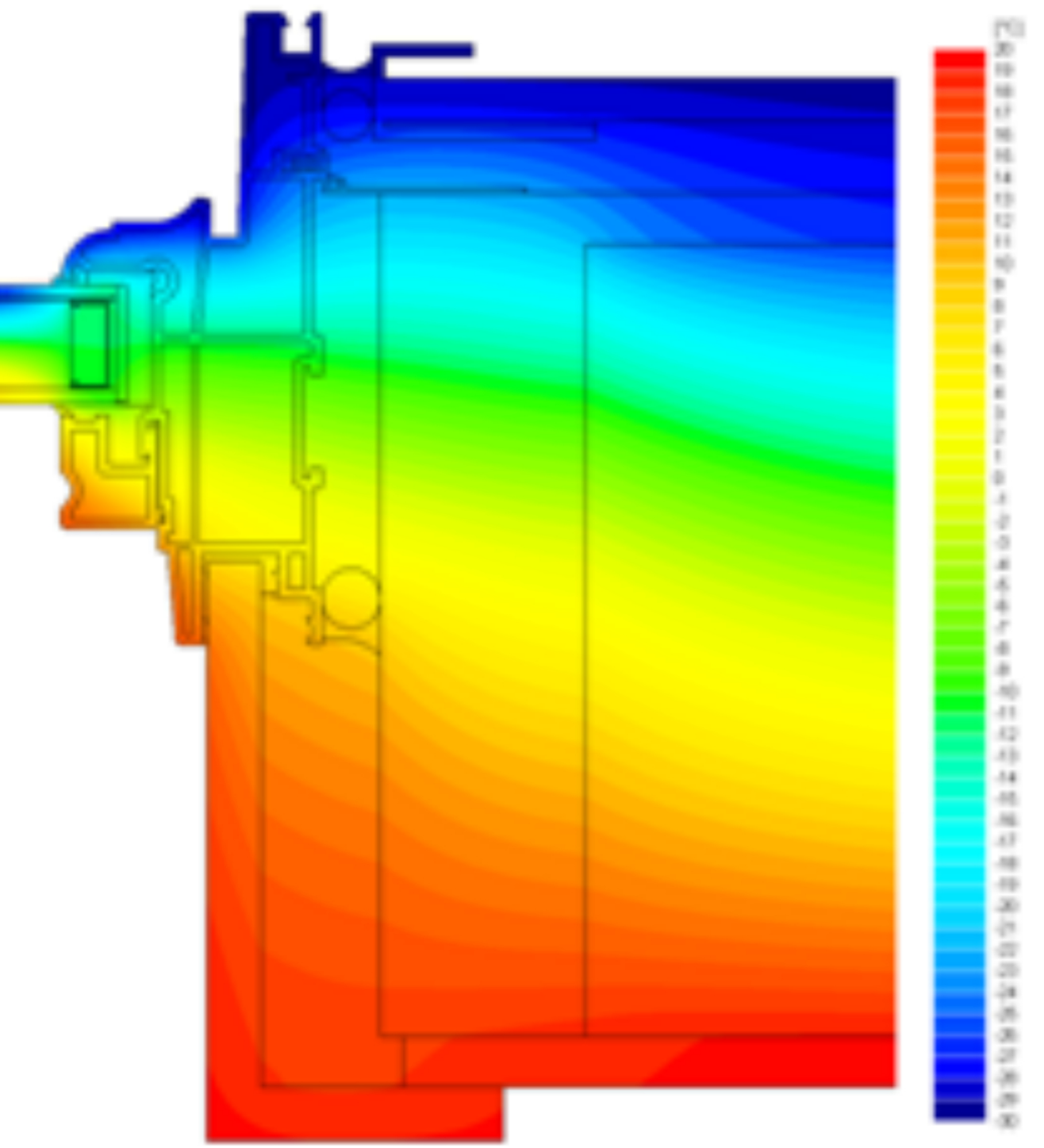




\section{Validation steady state simulation}

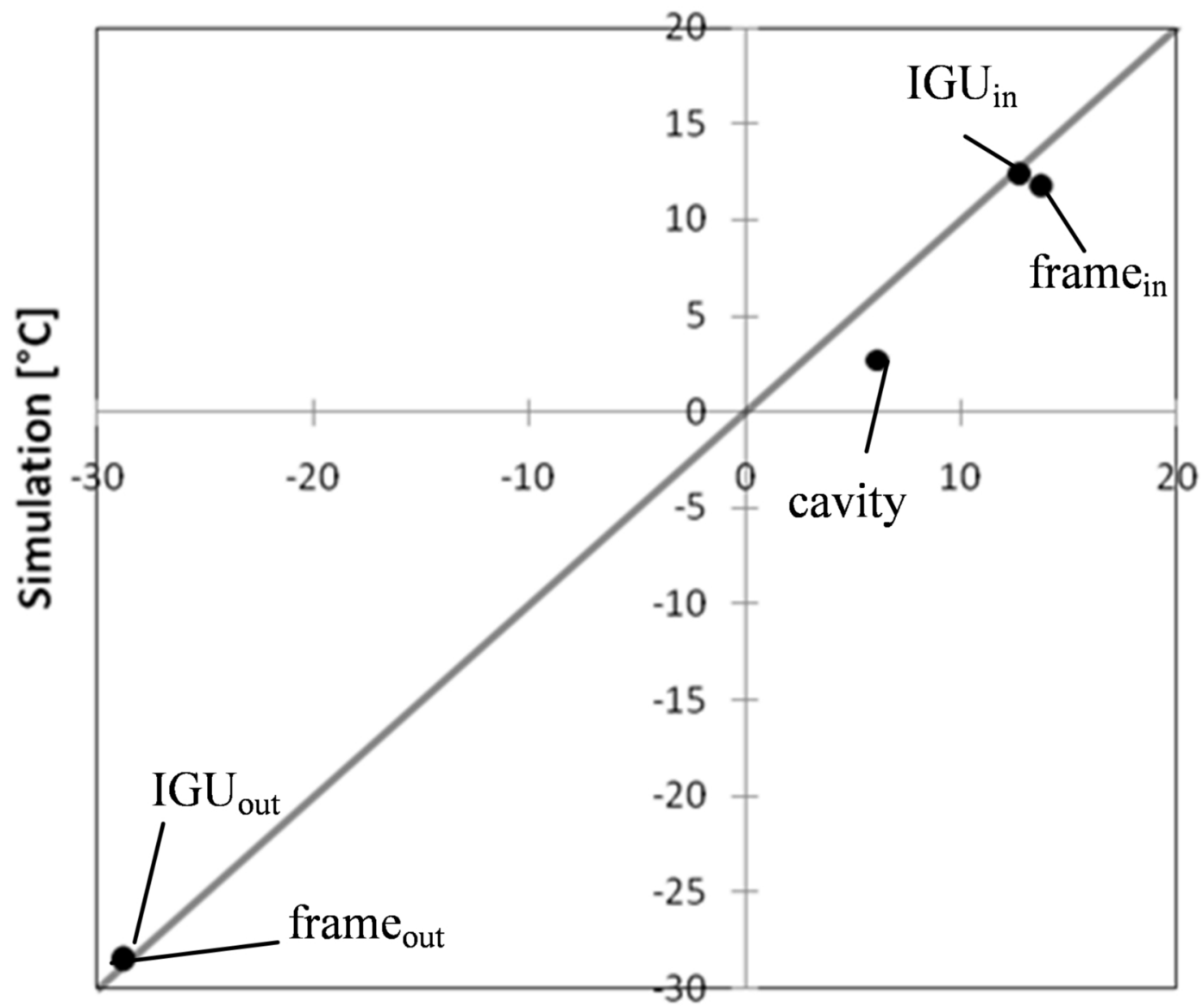

Experiment $\left[{ }^{\circ} \mathrm{C}\right]$ 


\begin{tabular}{l|l|l|}
\cline { 2 - 2 } Surface Temperature (corrected) & Legend & Temperature $\left({ }^{\circ} \mathrm{C}\right)$ at $0 \mathrm{~Pa}$ \\
\cline { 2 - 2 } & & Temperature $\left({ }^{\circ} \mathrm{C}\right)$ at $20 \mathrm{~Pa}$ \\
Test Set $\# 4$ & & Temperature $\left({ }^{\circ} \mathrm{C}\right)$ at $40 \mathrm{~Pa}$ \\
\hline
\end{tabular}

8

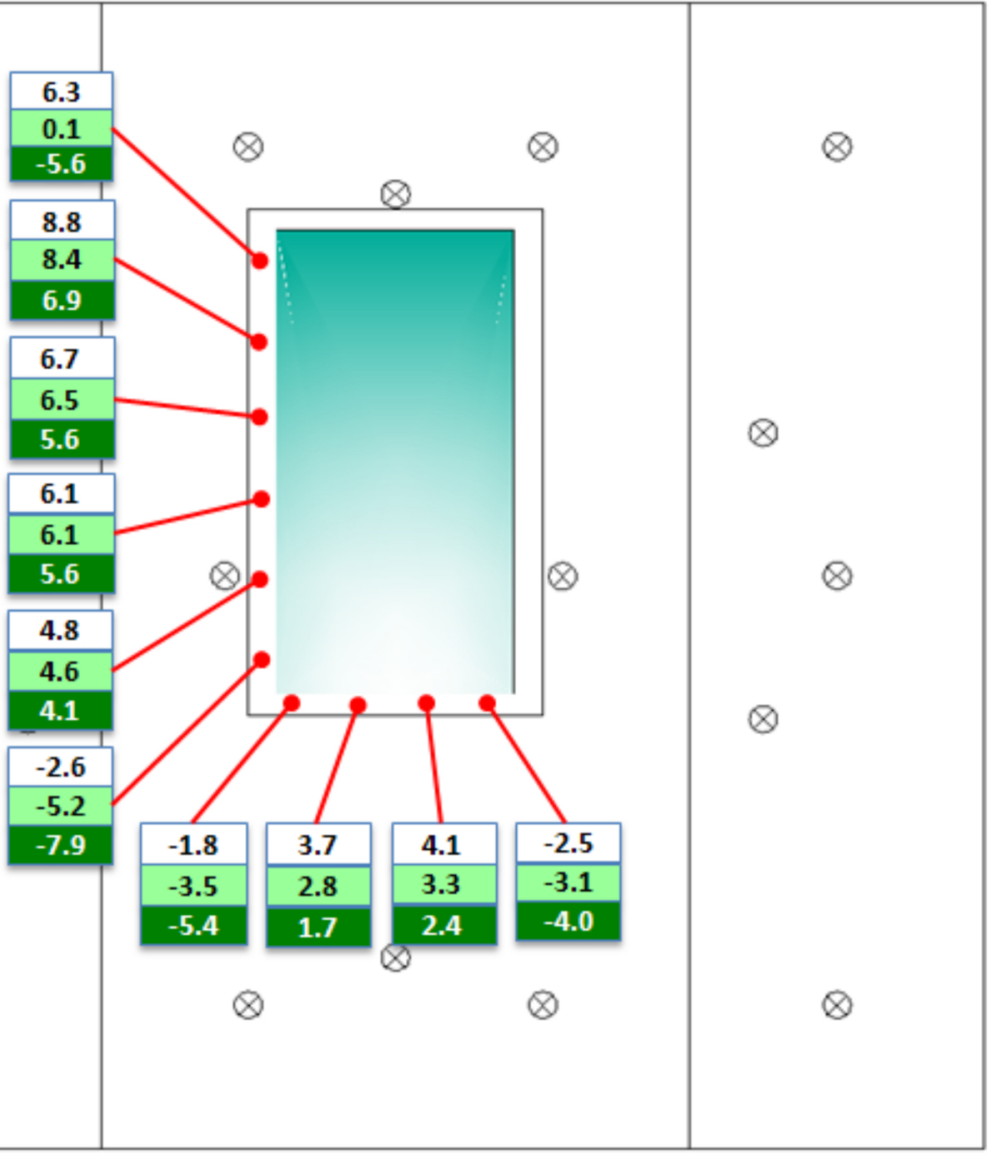

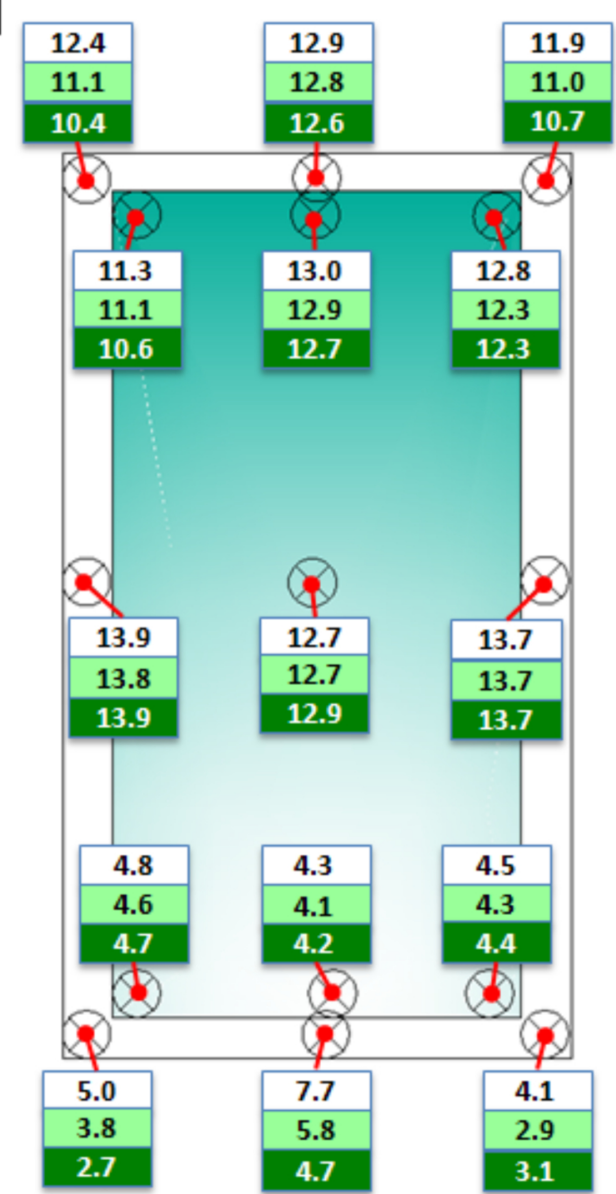


Temperature Index

Test Set \# 4

\section{Def 3}

\section{Legend \\ T Index at $\mathbf{0} \mathbf{P a}$ \\ TIndex at $20 \mathrm{~Pa}$ \\ T Index at $40 \mathrm{~Pa}$}

8

$$
\begin{array}{|l|}
\hline 0.74 \\
\hline 0.58 \\
\hline 0.45 \\
\hline
\end{array}
$$

$\otimes$

\begin{tabular}{|l|}
\hline 0.79 \\
\hline 0.76 \\
\hline 0.75 \\
\hline 0.74 \\
\hline 0.73 \\
\hline 0.72 \\
\hline
\end{tabular}

\begin{tabular}{|l|}
\hline 0.73 \\
\hline 0.72 \\
\hline 0.71 \\
\hline
\end{tabular}

\begin{tabular}{|l|}
\hline 0.70 \\
\hline 0.69 \\
\hline 0.68 \\
\hline
\end{tabular}

0.56

0.38

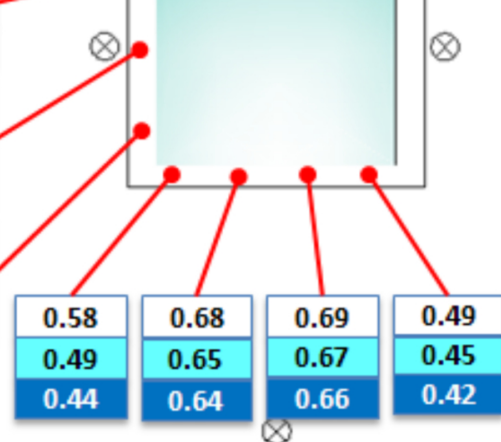

$\otimes$

$\otimes$

$\otimes$ $\otimes$

Q

8

$Q$

$\otimes$
8

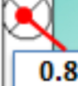

0.89

0.89

0.89
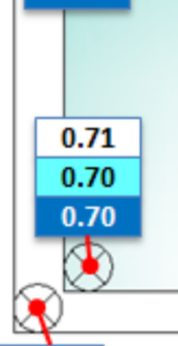

(a)

\begin{tabular}{|l|}
\hline 0.71 \\
\hline 0.66 \\
\hline 0.63
\end{tabular}

$Q$

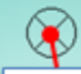

$$
0.87
$$

0.87

0.87

0.87
0.87

0.87

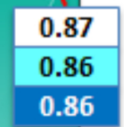

0.85

0.83

0.82

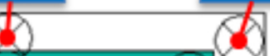


Temperature Index

Def 3

$40 \mathrm{~Pa}$

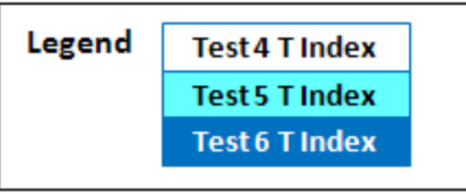

8

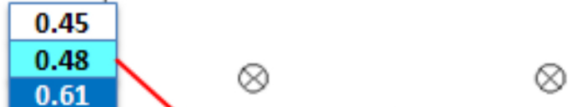

8
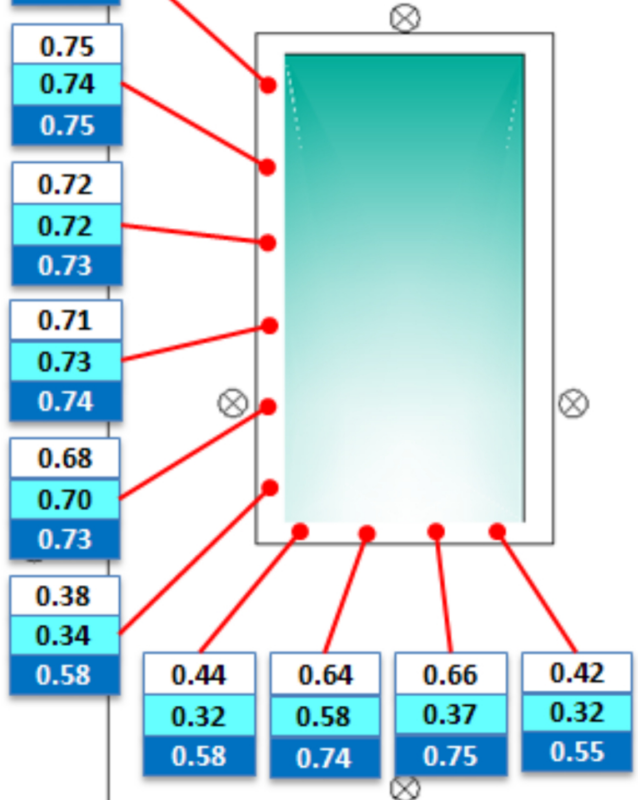

8

$\otimes$

$\otimes$

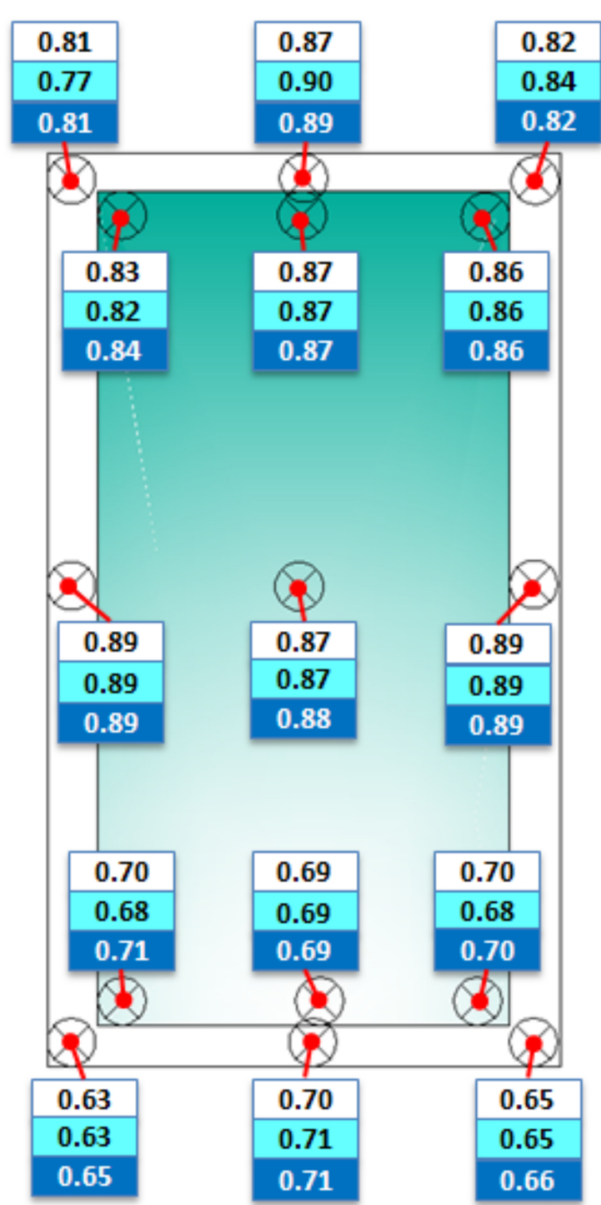

